DOI: https://doi.org/10.15688/mpcm.jvolsu.2018.4.5

UDC 519.872.5, 519.872.7

LBC 51.02

\title{
MULTICHANNEL NODES WITH IDENTICAL TIME OF SERVICE
}

\author{
Andrey Valerianovich Pavlov \\ Candidate of Physical and Mathematical Sciences, Associate Professor, \\ Department of Higher Mathematics-1, \\ MIREA - Russian Technological University \\ a_pavlov@mirea.ru \\ Prosp. Vernadskogo, 78, 119454 Moscow, Russian Federation
}

\begin{abstract}
The author investigates multichannel nodes in series with different service disciplines of service without an interruption of service in every node. Very big decrease of the virtual time of wait in inlying nodes is proved. Exact estimations of time of wait on the inlying nodes are resulted.
\end{abstract}

Key words: identical service, multi-channel nodes in series, total time of work, time of wait, disciplines of service.

\section{Introduction}

In the $[10 ; 11]$ works of author the nodes with one device in every node were explored. In the main section of the work the results are generalized in case of multichannel nodes in series (theorem 1). In theorem 1 a new estimation of the virtual time of wait for the inlying nodes is considered. From the estimation time of wait ensues too. A primary aim of the work is the proof of the fact, that the very big decrease of total work in inlying nodes is executed not only for one (the $[10 ; 11]$ works), but also for a few devices in one node in conditions of critical load and in conditions of overload $(\rho>1)$ on the first node. An estimations of the theorem 1 with $C(N)=2 N-1, V_{i}^{t} \leq \Delta(t)(2 N-1) / N$ are new (in the [12] work the similar theorem is only partly proved; the proof of the theorem 1 substantially shorter and simpler than in the [12] work). In particular, the time of wait in the node with $\infty$ the $i$ number $\left(V_{i}^{t}, i>1\right.$, a determination further) and the total time of work (in sum) on $\underset{\sim}{\sim}$ all nodes except the first are limited by a small constant, if on the first node the customers $>$ arrive with the limited maximal length. From the proof of theorem 1 we get the simple $\varangle$ similar theorem for all the service disciplines "without an interruption of service" in every o node (theorem 2).

Especially the interesting applications of results of the article follow from the example (2) of conclusion in the case of the determined time of service, when time of service by one 
device of any customer is equal to constant (for instance, the quantity of customers no more 3 for two devises in every node).

Similar descriptions for identical service in tandem nets were explored in Boxma and Vinogradov works [5-7]. But in the works the nets were mainly explored with one device in every node [5;7]. In the second part of article the methods of the authors are not used, we study the successive nodes with help of the identity of Legendre [10;11].

We will mark, that in difference from the first works on the theme of identical service, [7;9], all the theorems of the main part of article are proved a.s. for all input processes on the first node (without some limitations on the input process $A(t)$ ).

\section{Identical service}

We consider the consistently united nodes with the identical service: the length of service by one device of any customer is identical for every nodes and every devices, or

$$
\xi_{j}^{1}=\xi_{j}^{2}=\ldots=\xi_{j}^{K}, j=1,2, \ldots,
$$

where the random value $\xi_{j}^{i}$ is the time of service of customer with the $j$ number on the node with the $i$ number by one device (unit of service), if the service takes place without interruption; the different devices on every nodes are identical, where $\left\{\xi_{j}^{1}, j=1,2, \ldots\right\}$ are mutually independent random values with the distribution function $F(x)=\operatorname{Pr}\left(\xi_{j}^{1} \leq x\right)$. Further we will use for $\xi_{j}^{i}$ the term "length of customer" too.

We consider $K$ nodes, $K \geq 2$. The arrival process for node with the $j$ number is equal to the output process on the node with the $(j-1)$ number, $j=2, \ldots K$.

As soon as the service is finished the customer arrives on the next node. In the theorem 1 the customers are served in order of arrival in every node (the FIFO (FCFO) discipline of service), in the theorem 2 the order of service is definite before the theorem with help of the $D 1, D 2$ conditions. If a customers arrives on the first node in a group (for non-ordinary $A(t)$ process), the customers are disposed in the group in a random order all results of the theorems 1,2 do not rely on a order in the group.

The node with $\mathrm{j}$ number consists of $N$ service units (devices) with infinite quantity of wait places, $j=1, \ldots K$.

In the article we consider the random values:

- $W_{j}^{t}$ - the total time of service of all customers at the $t$ moment on the $j$ node, $j=1, \ldots, K$ ( the virtual time of wait for one channel at the $t$ moment);

- $V_{j}^{t}$ - the full time of service of customer arriving on the $j$ node at the $t$ moment (on the node with the $j$ number), $j=1, \ldots, K$ (the time of wait plus the "length of the customer").

By definition, $A(t)$ is the final customer number among all customers arriving on first node during $[0, t]$. If a customers arrives on the first node in a group, the customers are disposed in the group in a random order.

For the ordinary process

$$
A(t)=\max k: t_{k} \leq t, A(t)=0, \quad \text { if } t_{1}>t,
$$

where $t_{k}$ is the moment of arriving on the first node of the customer with $k$ number.

The process $A(t)$ and the $\left\{\xi_{j}^{1}, j=1,2, \ldots\right\}$ sequence are mutually independent (for all $t$ ). 
By definition, $v_{j}^{t}$ is the total quality of customers on the node with the $j$ number at the $t$ moment, $j=1, \ldots, K$.

Let $v_{j}^{0}=0$, for all $j=1, \ldots, K$.

In the theorem 1 we consider $N>1$ devices in every nodes, and the customers are served in order of arrival in every nodes.

Theorem 1. In the conditions of the second part the

$$
\max _{i=2, \ldots, K} \sup _{0 \leq t \leq T} W_{i}^{t} \leq C(N) \Delta(T), N>1, V_{i}^{t} \leq \Delta(t)(2 N-1) / N, t \in[0, \infty), N \geq 1,
$$

expressions take place, where $\Delta(t)=\max _{j \leq A(t)} \xi_{j}^{1}, C(N)=2 N-1, i=2, \ldots, K$ (for one device similar expressions with $C(1)=1$ were considered in the [11] work).

Proof. We introduce a new $Q_{j}(N)$ system on the node with the $j$ number with help of the $S 1$ and $S 2$ conditions, $j=1, \ldots, K$.

By definition, the $A(j, t)$ value is equal to the number of the last customer arriving on the node with the $j$ number during $[0, t], A(1, t)=A(t), j=1, \ldots, K$.

The S1 conditions.

For the $Q_{j}(N)$ system the arrival process is equal $A(j, t), j=1,2, \ldots, K$, as in main node with $j$ number.

The "length of customer" of every customers in the $Q_{j}(N)$ system equals to the lengths for the main system.

\section{The S2 conditions.}

The speed of service in the $Q_{j}(N)$ system is $N$ (the node with the $j$ number of the $Q_{j}(N)$ system contains 1 device, and the speed of work on the device is $\left.N\right), j \geq 1$.

By definition, $w_{j}^{t}$ is a sum of remaining "lengths of customers" on the node with the $j$ number at the $t$ moment for the $Q_{j}(N)$ system (some of remaining lengths are equal to the complete lengths) with the primary input process on the node with the $j$ number.

By definition, for primary system (not for $Q_{j}(N)$ system) $W_{* j}^{t}$ is the total sum of full "lengths of customers" on the node with the $j$ number at the $t$ moment, $j=1, \ldots, K$ (for $N=1, W_{* j}^{t}=W_{j}^{t}+\theta_{j}^{t}$, by definition, $\theta_{j}^{t}$ is the part of the "lengths of customer" is already served at the $t$ moment in the primary system on the $j$ node, $\theta_{j}^{t}=0$, if $W_{j}^{t}=0$, $j=1, \ldots, K, N=1$ ).

It is simply to check, that for $N>1$ the

$$
0 \leq W_{* j}^{t}-w_{j}^{t} \leq N \Delta(t)
$$

inequality takes place for all $t$, if the input process on the node with the $\mathrm{j}$ number is the same for the primary and the $Q_{j}(N)$ systems. To obtain the fact we can consider the $0=t_{1} \leq s_{1} \leq \ldots t_{k} \leq s_{k} \leq \ldots$, points on the axis of time, where $Z(t) \leq N-1$ for all $t \in\left[t_{k}, s_{k}\right), k=1, \ldots$, and $Z(t) \geq N$ for all $t \in\left[s_{k}, t_{k+1}\right), k=1, \ldots$, by definition, $Z(t)$ is the total number of the working devices in the node with the $j$ number for the primary system (all the processes are continuous on the right). It is obviously, $W_{* j}^{t}-$ $-w_{j}^{t} \leq W_{* j}^{t} \leq(N-1) \Delta(t)$ for all $t \in\left[t_{k}, s_{k}\right)$ ( we use $W_{* j}^{t} \geq w_{j}^{t} \geq 0$ for all $t$ ). For all $t \in\left[s_{k}, t_{k+1}\right), k=1, \ldots$, we can use $W_{* j}^{t}-w_{j}^{t} \leq W_{* j}^{s_{k}}-w_{j}^{s_{k}} \leq N \Delta(t)$ (the speed of service in the primary system is equal to $N$, and the speed of service in the $Q_{j}(N)$ system is $N$ or 0 , if $\left.t \in\left[s_{k}, t_{k+1}\right)\right), k=1, \ldots$; if a customer arrives on the next node at the $\tau \in\left[s_{k}, t_{k+1}\right)$ moment, one remaining length is substituted by other at the $\tau$ moment. We used the methods of the lemma 2.2 in the [2-4] articles too. 
From the definitions of the $W_{* j}^{t}, W^{t}$ values $w_{j}^{t} \leq W^{t} \leq W_{* j}^{t}$ and for all $t 0 \leq W^{t}-$ $-w_{j}^{t} \leq W_{* j}^{t}-w_{j}^{t}$,

$$
w_{j}^{t} \leq W^{t} \leq W_{* j}^{t}=w_{j}^{t}+r_{j}(t), r_{j}^{t}=W_{* j}^{t}-w_{j}^{t}, 0 \leq r_{j}^{t} \leq N \Delta(t), j=1, \ldots, K,
$$

with help of the (1) inequality.

We will estimate the $w_{j}^{t}$ value for $j \geq 2$.

One device works in the $Q_{j}(N)$ system; the speed of work in the $Q_{j}(N)$ system is equal to $N$ from the $S 2$ conditions, and we can use Borovkov ([1, p.41])

$$
w_{j}^{t}=S_{j}(t)-N t-\inf _{0 \leq u \leq t}\left(S_{j}(u)-N u\right), j=1, \ldots, K,
$$

where $S_{j}(u)$ is the total sum of lengths of service of customers (the total sum of "lengths of customer") arriving on the node with the $j$ number during $[0, t]$.

From the definition of the $w_{j}^{t}$ characteristics we get

$$
S_{j}(t)=S_{j-1}(t)-W_{*(j-1)}^{t}, j=2, \ldots, K, S_{1}(t)=\sum_{i=1}^{A(1, t)} \xi_{i}^{1}, A(1, t)=A(t),
$$

and from $(2)$

$$
\begin{gathered}
S_{j}(t)-N t=\left(S_{j-1}(t)-w_{j-1}^{t}\right)-r_{j-1}(t)-N t= \\
=\left(S_{j-1}(t)-\left[S_{j-1}(t)-N t-\inf _{0 \leq u \leq t}\left(S_{j-1}(u)-N u\right)\right]\right)-r_{j-1}(t)-N t= \\
=\inf _{0 \leq u \leq t}\left(S_{j-1}(u)-N u\right)-r_{j-1}(t),
\end{gathered}
$$

$j=2, \ldots, K, N>1, t \in[0, \infty)$.

After substitution in (3) we get

$$
\begin{gathered}
w_{j}^{t}=\inf _{0 \leq u \leq t}\left(S_{j-1}(u)-N u\right)-r_{j-1}(t)-\inf _{0 \leq u \leq t}\left[\inf _{0 \leq v \leq u}\left(S_{j-1}(v)-N v\right)-r_{j-1}(u)\right]= \\
=\inf _{0 \leq u \leq t}\left(S_{j-1}(u)-N u\right)-r_{j-1}(t)-\inf _{0 \leq v \leq u_{*}}\left(S_{j-1}(v)-N v\right)-r_{j-1}\left(u_{*}\right) \leq \\
\leq-r_{j-1}(t)+r_{j-1}\left(u_{*}\right), u_{*} \in[0, t),
\end{gathered}
$$

where in the last inequality we use

$$
\inf _{0 \leq u \leq t}\left(S_{j-1}(u)-N u\right)-\inf _{0 \leq v \leq u_{*}}\left(S_{j-1}(v)-N v\right) \leq 0,0 \leq u_{*} \leq t .
$$

From $r_{j-1}(t) \geq 0$ and (2) we obtain

$$
w_{j}^{t} \leq r_{j-1}\left(u_{*}\right) \leq N \Delta(t), N>1, j=2, \ldots, K .
$$

We can use $w_{j}^{t} \leq W_{j}^{t} \leq w_{j}^{t}+(N-1) \Delta(t), j=1, \ldots, K$ (we use the lemma 2.2 in the [2] article, or the fact is easily checked up directly after breaking of axis of time up on intervals by the $0 \leq s_{1} \ldots \leq s_{k} \ldots$ points too). We get

$$
W^{t} \leq w_{j}^{t}+(N-1) \Delta(t) \leq(2 N-1) \Delta(t), N>1, j=2, \ldots, K .
$$


For $w_{j}^{t}$ the theorem 1 is proved.

By definition, the customer with the $n(t)$ number arrives in the node with the $j$ number at the $t$ moment.

If $V_{j}^{t} \geq 0$, we obtain the

$$
V_{j}^{t} N+\sum_{i=1}^{N-1} \beta_{i}=W_{j}^{t}
$$

equality, where $\left\{\beta_{i}\right\}$ are some remaining "lengths of customers" in the moment of beginning of service of customer with the $n(t)$ number. We get $V_{j}^{t} N \leq W_{j}^{t}$, and $V_{j}^{t} \leq W_{j}^{t} / N \leq$ $\leq \Delta(t)(2 N-1) / N\left(\right.$ with help of $\left.\beta_{i} \geq 0, i=1, \ldots, N-1\right), j=2, \ldots, K, N \geq 1$.

In the theorem 2 we consider all disciplines of service "without an interruption of service": the customers are served by the units of service of every nodes without an interruption (the precise definition is in the $D 1, D 2$ conditions).

To determine the disciplines we shall use the $D 1, D 2$ conditions.

\section{Condition D1.}

The speed of service is the 1 for any unit of service, if the unit works. Exactly, in the node with the $j$ number the quality of working units is $\min \left(N, v_{j}^{t}\right)$ at the $t$ moment.

\section{Condition D2.}

If the customer arrives to some unit of service, the customer is served by the unit of service without interruption until the moment, when the customer leaves the node.

By definition, $d \in G$, if for the service discipline $d$ the $D 1$ and $D 2$ conditions take place.

Theorem 2. Let the $d_{j}, j=1, \ldots, K$, disciplines handle by the process of service in the node with the $j$ number, and $d_{j} \in G, j=1, \ldots, K, N \leq 1$.

For $W_{j}^{t}$ takes place all the results of the theorem $1, j=2, \ldots, K, t \in[0, \infty)$. (Not for the $V_{j}^{t}$ values).

Proof. The proof of the theorem 2 word for word repeats proof of theorem 1 (in proof of the theorem 1 the FIFO (FCFO) discipline was not used).

\section{Conclusions}

In example the most interesting application of the theorem 1 is considered in the case of the determined service in every node.

\section{Example.}

We consider $K$ consistently located devices with identical service, $N>1$. The total quality of customers on every node with numbers $j>1$ is not more $2 N-1$ (not more 1 , if $N=1,[10 ; 11])$, if the time of service of every customer by every device is the $m$ constant for every nodes: $v_{j}^{t} \leq 2 N-1$, for all $t \in[0, \infty), j=2, \ldots, K$, if $v_{j}^{0}=0, j=1, \ldots, K$, $\xi_{j}^{1} \equiv m=$ const $<\infty, j=1,2, \ldots,\left(v_{j}^{t}\right.$ is the total quality of customers on the node with the $j$ number at the $t$ moment).

The author marks an of principle role of my teacher professor Solovjev A.D. (19272001 ) in appearance of the work (on the seminar from the department of the theory of probability in Moscow University nam. Lomonosov in the laboratory corps A at 1977-1993 y.). 


\section{REFERENCES}

1. Borovkov A.A. Veroyatnostnye protsessy v teorii massovogo obsluzhivaniya [Probability Processes in Queuing Theory]. Moscow, Fizmatlit Publ., 1972. 368 p.

2. Pavlov A.V. Asimptoticheski optimalnye distsipliny obsluzhivaniya pri vysokoy nagruzke [Asymptotically Optimal Queue Disciplines in Heavy Traffic]. Teoriya veroyatnostey $i$ ee primeniya [Theory of Probability and Its Applications], 1990, vol. 35, no. 4, pp. 713-727. DOI: $10.1137 / 1135100$.

3. Pavlov A.V. Asimptoticheski optimalnye distsipliny obsluzhivaniya dlya nekotorykh mnogokanalnykh setey [The Asymptotically Optimal Disciplines of Service for Some MultiChannel Networks]. Teoriya veroyatnostey $i$ ee primeniya [Theory of Probability and Its Applications], 1991, vol. 36, no. 1, pp. 170-175. DOI: 10.1137/1136020.

4. Pavlov A.V. Dostovernoe prognozirovanie funktsiy predstavimykh $\mathrm{v}$ vide preobrazovaniy Laplasa ili Furye [Reliable Prognosis of the Functions in the Form of Transformations of Fourier Or Laplace]. Vestnik MGTU MIREA, 2014, vol. 3, no. 2, pp. $78-85$.

5. Vinogradov O.P. Dvukhfazovaya sistema s identichnym obsluzhivaniem [Two-Phase System with Identical Service]. Mat. zametki [Mathematical notes of the Academy of Sciences of the USSR], 1983, vol. 33, no. 1, pp. 141-146. DOI: 10.1007\%2FBF01141205.

6. Vinogradov O.P. O vykhodyashchem potoke i sovmestnom raspredelenii vremen prebyvaniya $\mathrm{v}$ mnogofazovoy sisteme s identichnym obsluzhivaniem [On the Output Stream and Joint Distribution of Sojourn Times in a Multiphase System with Identical Service]. Teoriya veroyatnostey $i$ ee primeniya [Theory of Probability and Its Applications], 1995, vol. 40, no. 3, pp. 646-654. DOI: 10.1137/1140066.

7. Boxma O.J. On a Tandem Queueing Model with Identical Service Times at Both Counters, I. Advan. Appl. Probal., 1979, vol. 11, no. 3, pp. 616-643. DOI: 10.2307/1426958.

8. Boxma O.J. On a Tandem Queueing Model with Identical Service Times at Both Counters, II. Advan. Appl. Probal., 1979, vol. 11, no. 3, pp. 644-659. DOI: 10.2307/1426959.

9. Boxma O.J., Deng Q. Asymptotic behaviour of tandem queueing system with identical service times at both queues. Math. meth. of oper. res., 2000, vol. 52, iss. 2, pp. 307-323. DOI: 10.1007/s186-000-8317-z.

10. Pavlov A.V A net with serial access and the reduction of total work for identical service. Optimiz. and Inform. Comput., 2017, vol. 5, no. 2, pp. 121-126. DOI: 10.19139/soic.v5i2.244.

11. Pavlov A.V. Diffusion approximations and variation of conditions of ergodicity for identical service. Advan. Math. Scien., 1997, vol. 52, no. 3, pp. 171-172. DOI: 10.1070/RM1997v052n03ABEH001816.

12. Pavlov A.V. The disciplines of service with prior to the shortest and identical service. Moscow, MGTUREA (MIREA), 2014. 119 p.

13. Pavlov A.V. Identical service and the odd or even transform of Laplace. Anal. and comp. meth. in probab. theor. and its appl.(ACMPT2017). Moscow, Moscow University nam M.V. Lomonosov, 2017, pp. 31-35. 


\section{ПОСЛЕДОВАТЕЛЬНЫЕ МНОГОКАНАЛЬНЫЕ УЗЛЫ ДЛЯ ИДЕНТИЧНОГО ОБСЛУЖИВАНИЯ}

\section{Андрей Валерианович Павлов}

Кандидат физико-математических наук, доцент кафедры высшей математики-1, МИРЭА - Российский технологический университет a_pavlov@mirea.ru

просп. Вернадского, 78, 119454 г. Москва, Российская Федерация

Аннотация. Рассматриваются многоканальные последовательные узлы при идентичном обслуживании при произвольной нагрузке на первый узел. Отмечается ограниченность очереди при ограниченной длине требования. Доказано, что с точки зрения времени ожидания на внутренних узлах третий прибор является лишним.

Ключевые слова: идентичное обслуживание, многоканальные последовательные узлы, суммарная работа, время ожидания, дисциплины обслуживания. 